\title{
MEVCUT BETONARME YAPILARIN DEPREM PERFORMANSININ ANALIZI
}

\author{
Metin Hakan SEVERCAN ${ }^{1}$ (ORCID:0000-0001-7320-8409)* \\ Besian SINANI ${ }^{2}$ (ORCID:0000-0001-5424-6784) \\ ${ }^{I}$ İnşaat Mühendisliği Bölümü, Mühendislik Fakültesi, Niğde Ömer Halisdemir Üniversitesi, Niğde, Türkiye \\ ${ }^{2}$ Civil Engineering Department, University for Business and Technology, Priştina, Kosova
}

Geliş/Received: 12.11 .2018 Kabul / Accepted: 22.04.2019

\begin{abstract}
ÖZ
Bu çalı̧̧mada, Deprem Bölgelerinde Yapılacak Binalar Hakkında Yönetmelik 2007 (DBYBHY-2007) ve Eurocode 8 kullanılarak mevcut yapıların performansları belirlenmiştir. Örnek olarak 8 katlı bir adet mevcut betonarme yapı ele alınmıştır. Bu yapının performans değerlendirmesi, hem Deprem Bölgelerinde Yapılacak Binalar Hakkında Yönetmelik 2007 hem de Eurocode 8'de belirtilen şartlara göre doğrusal olmayan elastik yöntemlerden biri olan statik itme analizi yöntemi kullanılarak yapılmıştır. Analiz sonucunda elde edilen değerler doğrultusunda eleman hasar düzeyleri ve yapı performansları her iki yönetmeliğe göre karşılaştırılmıştır.
\end{abstract}

Anahtar kelimeler: Deprem Bölgelerinde Yapılacak Binalar Hakkında Yönetmelik 2007, eurocode 8, doğrusal olmayan hesap yöntemleri, statik-itme analizi, performans değerlendirmesi.

\section{ANALYSIS OF SEISMIC PERFORMANCE OF EXISTING REINFORCED STRUCTURES}

\begin{abstract}
In this study, the performances of existing reinforced structures are determined by using Turkish Seismic Code (TSC-2007) and Eurocode 8. The performance evaluation of eight story existing reinforced structure are made by using static pushover analysis method which is a nonlinear elastic method according to the conditions stated in both TSC-2007 and Eurocode 8. The performances of existing reinforced structures and the damage levels of elements obtained in analysis results are compared according to two codes.
\end{abstract}

Keywords: Turkish Seismic Code 2007, Eurocode 8, nonlinear elastic calculation methods, static pushover analysis, performance evaluation.

\section{GİRiș}

Son yıllarda yaşadığımız depremler ve can kayıpları ile birlikte, nüfusun $\% 45^{\prime}$ inin 1 . Derece deprem bölgesinde yaşadığı ülkemizde depreme dayanıklı yapı analizi ve tasarımı konusu daha çok önem kazanmıştır. Bu konu hakkında hem yurt dışındaki hem de yurt içindeki akademisyenler tarafindan araştırmalar yapılmış ve yapılmaya da devam etmektedir.

*Corresponding author / Sorumlu yazar. Tel.: +90 38822523 09; e-mail / e-posta: msever@ ohu.edu.tr 
DBYBHY-2007 Bölüm 7'ye göre, mevcut yapıların deprem performans1 Doğrusal Elastik veya Doğrusal Elastik Olmayan analiz yöntemleri ile belirlenebilmektedir. Bundan önceki yönetmeliklerde genel anlamda binanın küçük depremleri hasarsız atlatması, büyük depremleri can güvenliğini sağlayan sınırlı hasarla atlatması ve çok büyük depremleri de toptan göçme olmadan atlatması gibi performans seviyeleri hedeflenmiştir. DBYBHY-2007'de binaların performansa dayalı değerlendirmesinde bu amaçlar daha belirgin olarak tanımlanmış, deprem etkisi altında yapıdan beklenen performans seviyesinin ortaya çıkması için kullanılacak yöntemler belirlenmiştir. Mevcut bina performansının doğrusal elastik yöntem ile belirlenmesi çok büyük kolaylıklar getirmekte ve mevcut bilgisayar çözümleme programlarının kullanılmasını mümkün kılmaktadır.

Yapıların performansına ilişkin birçok araştırmacı çeşitli çalışmalarda bulunmuşlardır. Kıran [1], binaların performans analizi için kullanılan doğrusal ve doğrusal olmayan analiz yöntemlerinin incelenmesi konusunda araştırma yapmıştır. Birol [2], az ve çok katlı yapılarda bilgi düzeyi seviyesinin binanın performansına olan etkisini incelemiştir. Gökalp [3], betonarme yapıların performans analizlerinde kullanılan yöntemleri karşılaştırmıştır. Yıldırım [4], bodrum kat ve yedi normal kattan oluşan sekiz katlı betonarme bir konut yapısının betonarme perde ve kolonlardan oluşan taşıyıcı sisteminin deprem performansına etkisini araştırmıştır. Bjarnason [5], mevcut betonarme yapıların doğrusal olmayan analiz yöntemleri ile performans analizleri üzerinde çalışmalar yapmıştır. Bozan [6], mevcut çok katlı yapının statik itme (pushover) yöntemi ile analizi üzerinde çalışmalar yapmıştır. Ekici [7], yönetmeliklerde verilen yapı performans limitleri ile gözlemlenen yapısal hasarları karşılaştırmıştır. Toprak [8], lineer ve nonlineer yaklaşımlar kullanarak yapıların deprem performanslarını değerlendirmiştir. Temür [9], statik itme (pushover) yöntemini kullanarak yapıların analizi üzerinde çalışmalar yapmıştır. Öztürk [10], sismik olarak aktif olan ve yakın fay bölgelerinde bulunan yapıların sismik kayma tepkisini incelemiştir.

Bu çalışmada taşıyıcı sistemi çerçevelerden oluşan, düzenli bir aks sistemine sahip mevcut 8 katlı bir yapı, uluslararası kabul görmüş bir mühendislik yazılımı olan Sap2000 V.16 programında modellenmiştir. Modellenen bu yapının analizi doğrusal olmayan analiz yöntemlerinden biri olan statik itme (Pushover) yöntemi kullanılarak hem DBYBHY-2007'ye göre hem de Eurocode 8'e göre yapılmıştır. Performans analizinde dikkate alınan bu iki yönetmelik sonucu elde edilen eleman hasar düzeyleri ve yapı performansları karşılaştırılmıştır.

\section{MATERYAL VE METOT}

Performans değerlendirilmesi yapılan 8 katlı yapı $\mathrm{X}$ yönünde 3 açıklıklı, Y yönünde ise 4 açıklıdır. Yapı toplam uzunluğu X yönünde $18 \mathrm{~m}$ iken $\mathrm{Y}$ yönünde $24 \mathrm{~m}$ ve kat yüksekliği 3 m'dir. Kullanım amacı konut olarak tasarlanan yapı zemin kat ve 7 normal kattan oluşmaktadır. Bu yapı mevcut bir bina olarak kabul edilmiş ve kapsamlı bilgi düzeyinde incelenmiştir. Düzenli aks sistemine sahip sadece çerçevelerden oluşan binanın üç boyutlu taşıyıcı sistem modeli ve kalıp planı Şekil 1'de, binanın malzeme kalitesi ve sismik parametreleri ise Tablo 1'de verilmiştir.

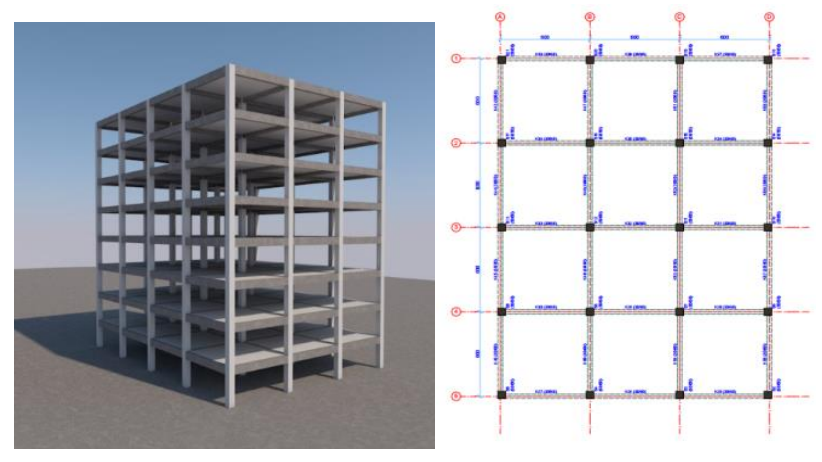

Şekil 1.Yapının 3 boyutlu taşıyıcı sistem modeli ve kalıp planı 
Tablo 1. Binanın malzeme kalitesi ve sismik parametreleri

\begin{tabular}{|c|c|c|c|}
\hline \multicolumn{2}{|c|}{ Malzemeler } & Statik & Deprem Parametreleri \\
\hline Beton Sinıfi & $\mathrm{C} 20 / 25$ & $\begin{array}{c}f_{\mathrm{ck}}=20 \mathrm{~N} / \mathrm{mm}^{2} \\
\mathrm{E}: 28000 \mathrm{~N} / \mathrm{mm}^{2}\end{array}$ & Deprem Bölgesi: 1. Derece \\
\hline Donatı Sinıfı & S420 & $\begin{array}{c}\mathrm{f}_{\mathrm{yk}}=420 \mathrm{~N} / \mathrm{mm}^{2} \\
\mathrm{E}=200000 \mathrm{~N} / \mathrm{mm}^{2}\end{array}$ & $\begin{array}{c}\text { Zemin Sinit1: } \angle 3 \\
\text { Spektrum Karakteristik Periyotlar1: } \mathrm{T}_{\mathrm{a}}=0.15, \mathrm{~T}_{\mathrm{b}}=0.6\end{array}$ \\
\hline
\end{tabular}

\subsection{Binanın Modellenmesi}

Kiriş kesitleri $(25 \times 60) \mathrm{cm}$, kolon kesitleri $(50 \times 50) \mathrm{cm}$, döşeme kalınlıkları ise $16 \mathrm{~cm}$ olarak kabul edilmiş ve yap1 bu şekilde Sap2000 V.16 programı ile modellenmiştir. Döşeme yükleri hesaplanarak dikdörtgen kesitli olarak tanımlanan kirişlere aktarılmıştır. Döşemeler yatayda rijit diyafram olarak tanımlanmış olup düğüm noktaları sonsuz rijit kabul edilmiştir.

\subsection{Eşdeğer Deprem Yüklerinin Hesabı}

Bina mod şekillerinin ve titreşim periyotlarının belirlenebilmesi için her katta üçer adet olmak üzere toplam mod sayısı 24 olarak belirlenmiş ve yapı modal olarak analiz edilmiştir. Analiz sonucunda x yönüne ait birinci doğal titreşim periyodu 1.38850 sn ve y yönüne ait doğal titreşim periyodu 1.35082 sn olarak elde edilmiştir. DBYBHY2007 Bölüm 7.5.1.1'e göre $\mathrm{Ra}=1$ alınmıştır[11].

\subsection{Kirişlerde ve Kolonlarda Plastik Mafsal Özelliklerinin Tanımlanması}

Kirişlerin ve kolonların plastik mafsal özellikleri, SAP2000 V.16 programında ilgili elemanın net açıklıklarının uçlarına tanımlanmıştır. Programa plastik mafsal özelliklerinin veri girişi kiriş ve kolonlar için sırasıyla Şekil 2'de verilmiştir [12].
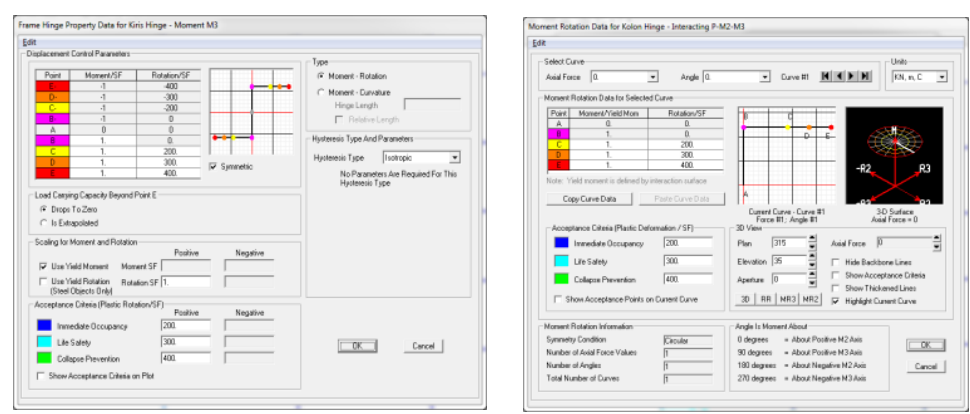

Şekil 2. Kirişlerin ve kolonların plastik mafsal özellikleri

Kirişlerin ve kolonların kesit özellikleri Xtract programı yardımıyla hesaplanmıştır. Belirtilen programda veri olarak, kesit boyutları, pas payları, donatı boyutları, donatı düzeni, S420 çelik, C20 sargılı ve sargısız beton modelleri için gerilme-şekil değiştirme parametreleri DBYBHY-2007 Bilgilendirme Eki 7B'ye göre tanımlanmıştır. Xtract programı kullanılarak, yukarıda tanımlanan bilgiler doğrultusunda kiriş kesitine ait moment eğrilik diyagramı, malzeme özelliklerinin şekil değiştirme ve eğrilik değerleri hesaplanmaktadır[11].

\subsection{Artımsal İtme Analizi (Pushover Analizi)}

Statik itme analizi iki kısımdan oluşmaktadır. İlk kısımda düşey yükler (G+0.3Q) dikkate alınarak doğrusal olmayan analiz, ikinci kısımda ise yatay yükler altında artımsal itme analizi kullanılarak yapılmaktadır. Yapılan artımsal itme analizi sonucunda X ve Y yönünde elde edilen statik itme eğrisi Şekil 3’te verilmiştir. 


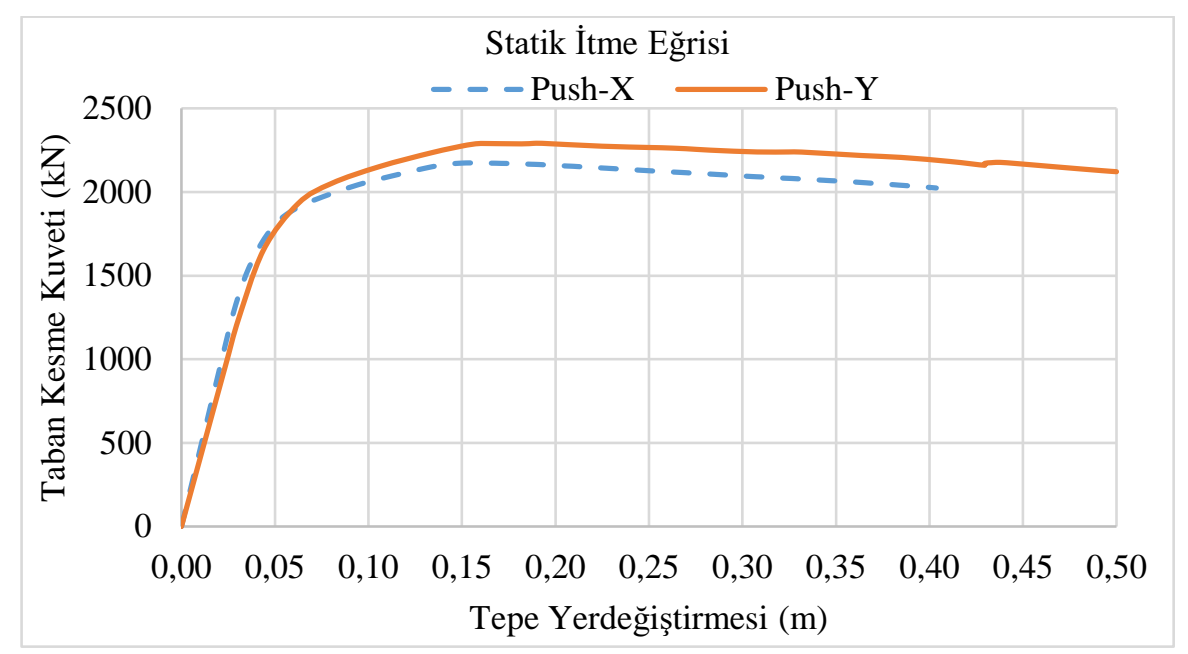

Şekil 3. X ve Y yönü için statik itme eğrisi

\subsection{Modal Kapasite Diyagramının Elde Edilmesi}

Her iki yönde elde edilen statik itme eğrilerinin modal kapasite diyagramına dönüştürülmesi için etkin kütle ve modal katılım oranının belirlenmesi DBYBHY-2007, Bölüm 7.6.5.4'e göre yapılmıştır. Statik itme eğrisi, X doğrultusunda birinci moda ait katılım oranı, birinci moda ait mod şekli, genliği ve etkin kütle değerlerinden faydalanılarak, modal kapasite diyagramına dönüştürülmüştür.

DBYBHY-2007 Bölüm 7.6.5.4'te tanımlanan Denk (7.1) ve Denk (7.2) kullanılarak X ve Y yönündeki statik itme eğrisinin modal ivme-modal yerdeğiştirme diyagramına dönüştürülmesi için hesaplanan modal kapasite diyagramının koordinatları kullanılarak modal kapasite diyagramları elde edilmiştir[11].

\subsection{Modal ve Tepe Yer Değiştirme Talebinin Hesabı}

X ve Y yönünde son itme adımındaki modal yer değiştirme talebi DBYBHY-2007 Bilgilendirme Eki 7C'ye göre; tepe yer değiştirme talebi ise DBYBHY-2007 7.6.5.7'ye göre belirlenmiştir.

$\mathrm{X}$ yönü modal yer değiştirme talebi: $\mathrm{u}_{\mathrm{xN} 1}^{(\mathrm{p})}=\Phi_{\mathrm{xN} 1} \Gamma_{\mathrm{x} 1} \mathrm{~d}_{1}^{(\mathrm{p})}=0.0242 \times 52.674 \times 0.32=0.408 \mathrm{~m}$

Y yönü modal yer değiştirme talebi: $u_{\mathrm{xN} 1}^{(\mathrm{p})}=\Phi_{\mathrm{yN} 1} \Gamma_{\mathrm{y} 1} \mathrm{~d}_{1}^{(\mathrm{p})}=0.0243 \mathrm{x} 52.74 \times 0.249=0.319 \mathrm{~m}$

$\mathrm{X}$ ve Y yönünde bulunan tepe yer değiştirme istemine ulaşıncaya kadar yeni bir itme analizi SAP2000 V.16 programı yardımıyla yapılmıştır. Bu analiz sonucunda oluşan plastik dönme ve iç kuvvet talepleri belirtilen programdan alınmıştır. X yönünde yapılan itme analizinden binanın tepe deplasmanı talebine ulaşıldığı adımda oluşan plastik mafsallar Şekil 4’te görülmektedir[11].

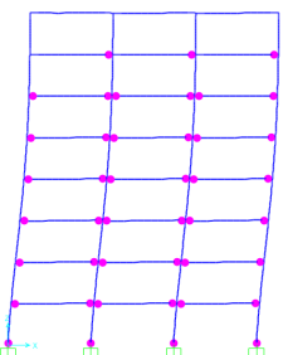

a) X yönü

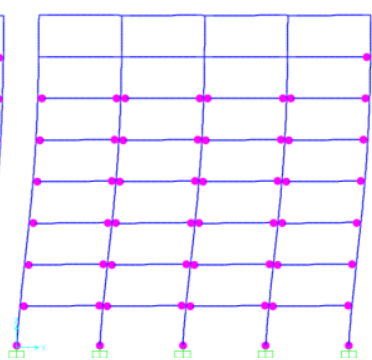

b) Y yönü

Şekil 4. X ve Y yönünde yapılan itme analizi sonucunda binada oluşan plastik kesitler 


\subsection{Kolonların ve Kirişlerin Birim Şekil Değiştirme Taleplerinin Hesabı}

Kolonlar için P-M2-M3 mafsal tanımı ve kirişler için ise M3 mafsal tanımı yapılarak itme analizi gerçekleştirilmiştir. SAP2000 V.16 programı ile her iki yönde tepe yer değiştirme talebine ulaşıncaya kadar yapılan itme analizi sonucu elde edilen plastik dönme değeri plastik mafsal boyuna bölünerek plastik eğrilik değeri elde edilmiş ve bu değerle Xtract programından alınan akma eğrilik değeri toplanarak toplam eğrilik değeri elde edilmiştir. Daha sonra Xtract programıyla DBYBHY-2007 Bölüm 7.6.9'da verilen hasar sınırları için tanımlanan birim şekil değiştirme değerleri kullanılarak elde edilen deprem etkisinde normal kuvvet talebi altında moment eğrilik ilişkisini gösteren "Normal Kuvvet-Eğrilik" diyagramı kullanılarak kesitin hasar sınırı tespit edilmiştir. Her iki yönde kritik katta kolonlar için elde edilen eksenel kuvvet ve toplam eğrilik değerleri "Normal Kuvvet-Eğrilik" diyagramında gösterilerek her bir kolon elemanının hasar düzeyleri belirlenmiş ve Şekil 5'te gösterilmiştir. Ayrıca, kritik katta her iki doğrultuda kirişler için elde edilen toplam eğrilik değerleri "Normal Kuvvet-Eğrilik" diyagramında gösterilerek her bir kiriş elemanının hasar düzeyleri belirlenmiş ve Şekil 6'da gösterilmiştir.

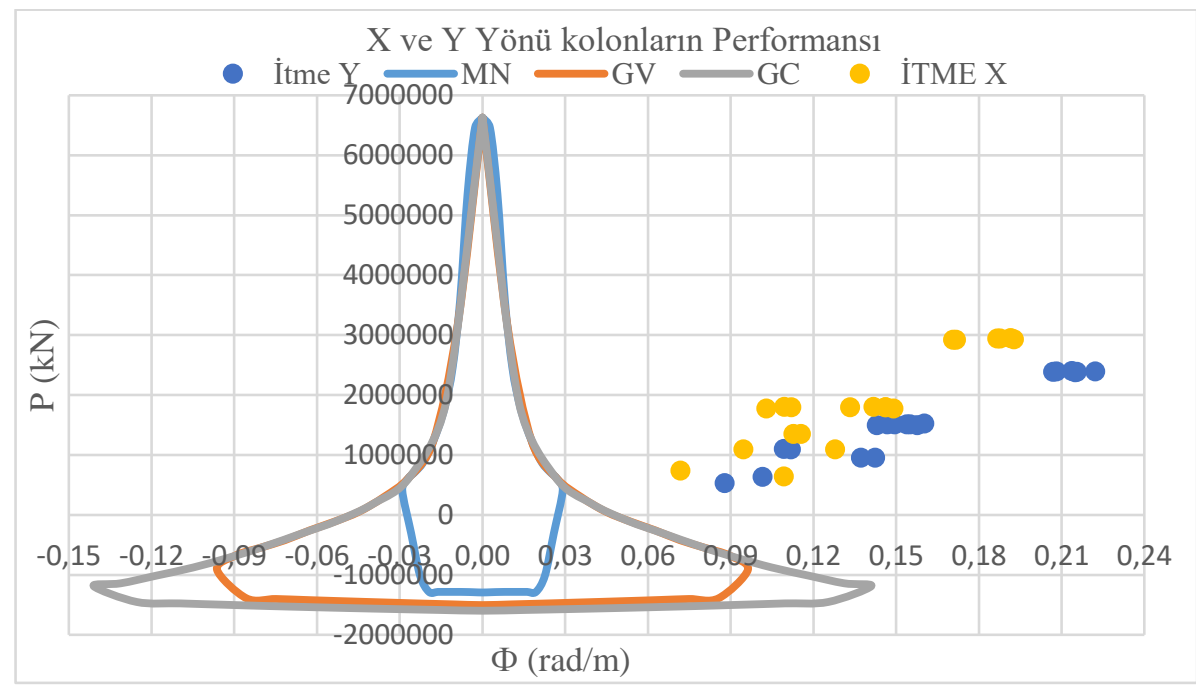

Şekil 5. Kritik kattaki kolonların X ve Y yönünde belirlenen performans değerleri

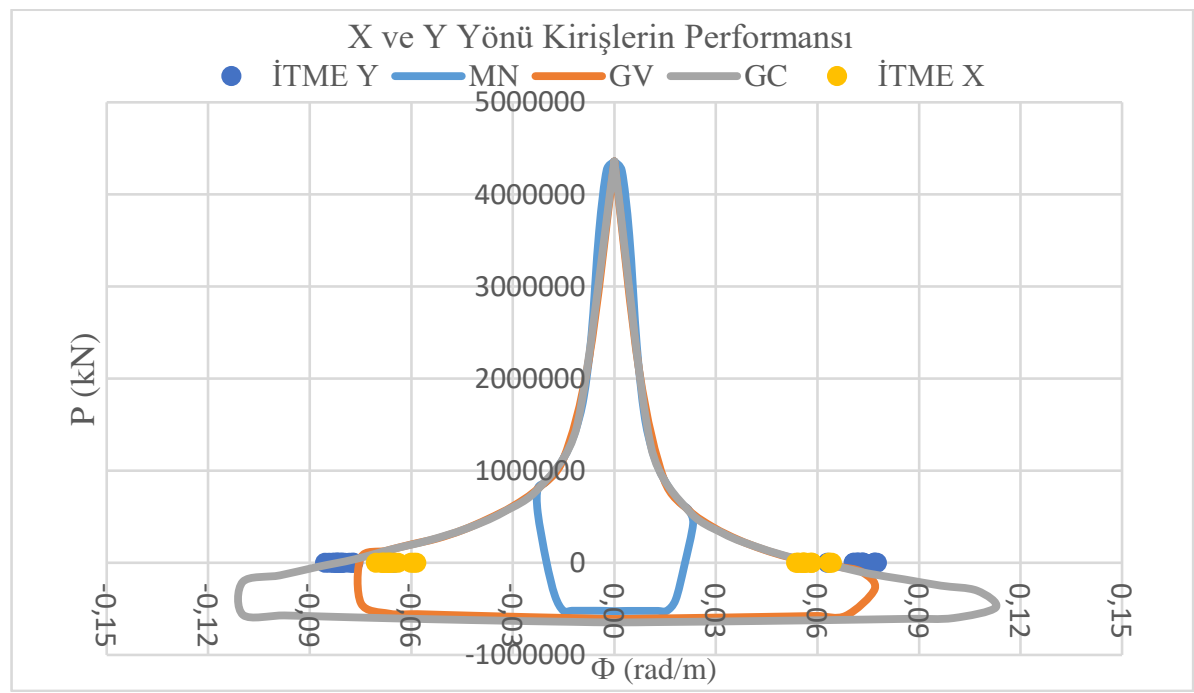

Şekil 6. Kritik kattaki kirişlerin $\mathrm{X}$ ve $\mathrm{Y}$ yönünde belirlenen performans değerleri 


\subsection{Eleman Hasar Düzeyleri Ve Bina Performansının Belirlenmesi}

Doğrusal elastik olmayan yöntemlerden artımsal eşdeğer deprem yükü yöntemi ile itme analizi sonucuna göre kritik katta bulunan kolon ve kirişlerin her iki yöndeki eleman hasar düzeyleri belirlenmiş ve sırasıyla Tablo 2 ve Tablo 3'te verilmiştir.

Şekil 7 ve şekil 8'de sırasıyla X ve Y yönünde kritik katta bulunan kolon ve kiriş elemanlarının hasar düzey yüzdeleri verilmiştir. Şekil 7'de görüldüğü üzere X yönünde kritik kattaki kolonların tamamı (\%100) göçme bölgesi hasar düzeyinde çıkmıştır. Kritik katta bulunan kirişler için yapılan değerlendirmede, $\mathrm{X}$ yönünde kirişlerin \% 53.33'ü belirgin hasar düzeyinde, \% 26.67'si ileri hasar düzeyinde, \% 20'si ise göçme bölgesi hasar düzeyinde çıkmıştır. Şekil 8 incelendiğinde, Y yönünde kritik kattaki kolon ve kirişlerin tamamının (\%100) göçme bölgesinde olduğu görülmüştür. Bu sonuçlara ve DBYBHY-2007 madde 7.7'de belirtilen performans kriterlerine göre 8 katlı örnek binanın "Göçme Durumu” performans seviyesinde olduğu belirlenmiştir.

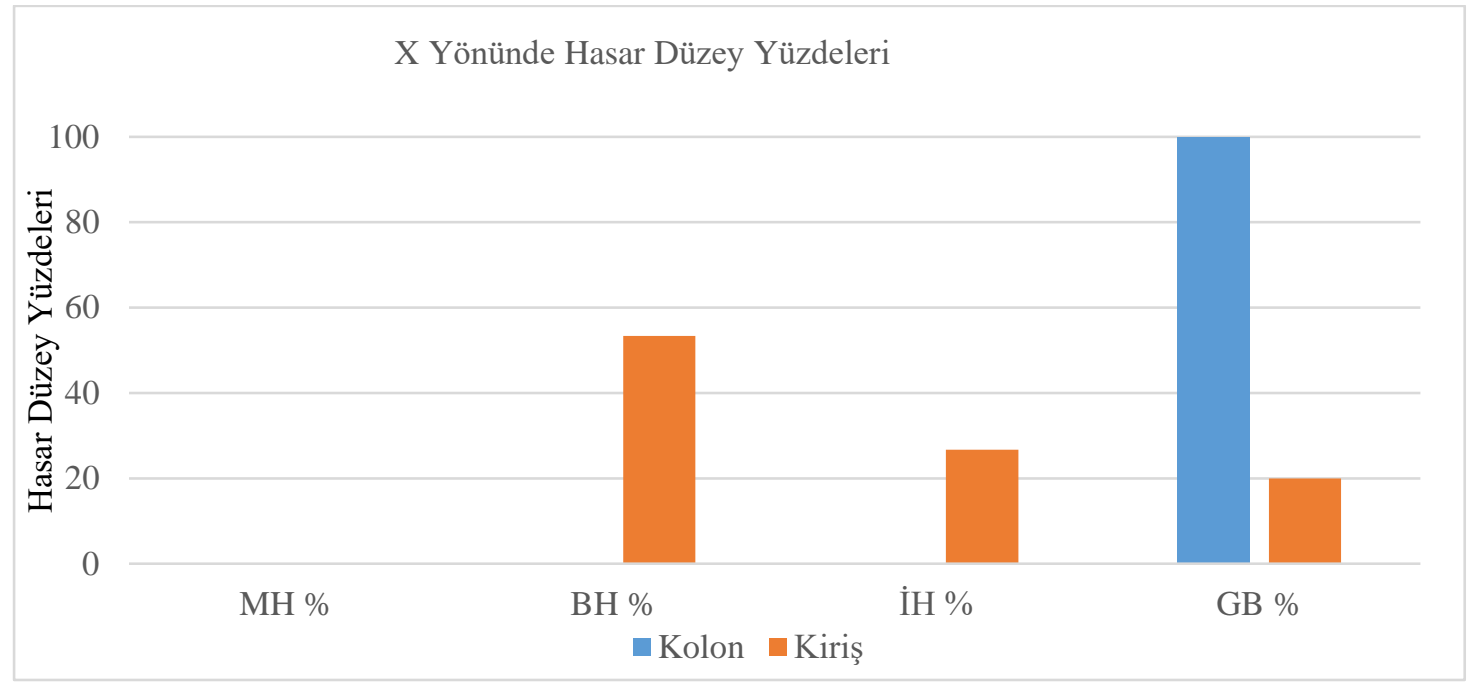

Şekil 7. X yönünde taşıyıcı sistem elemanları hasar düzey yüzdeleri

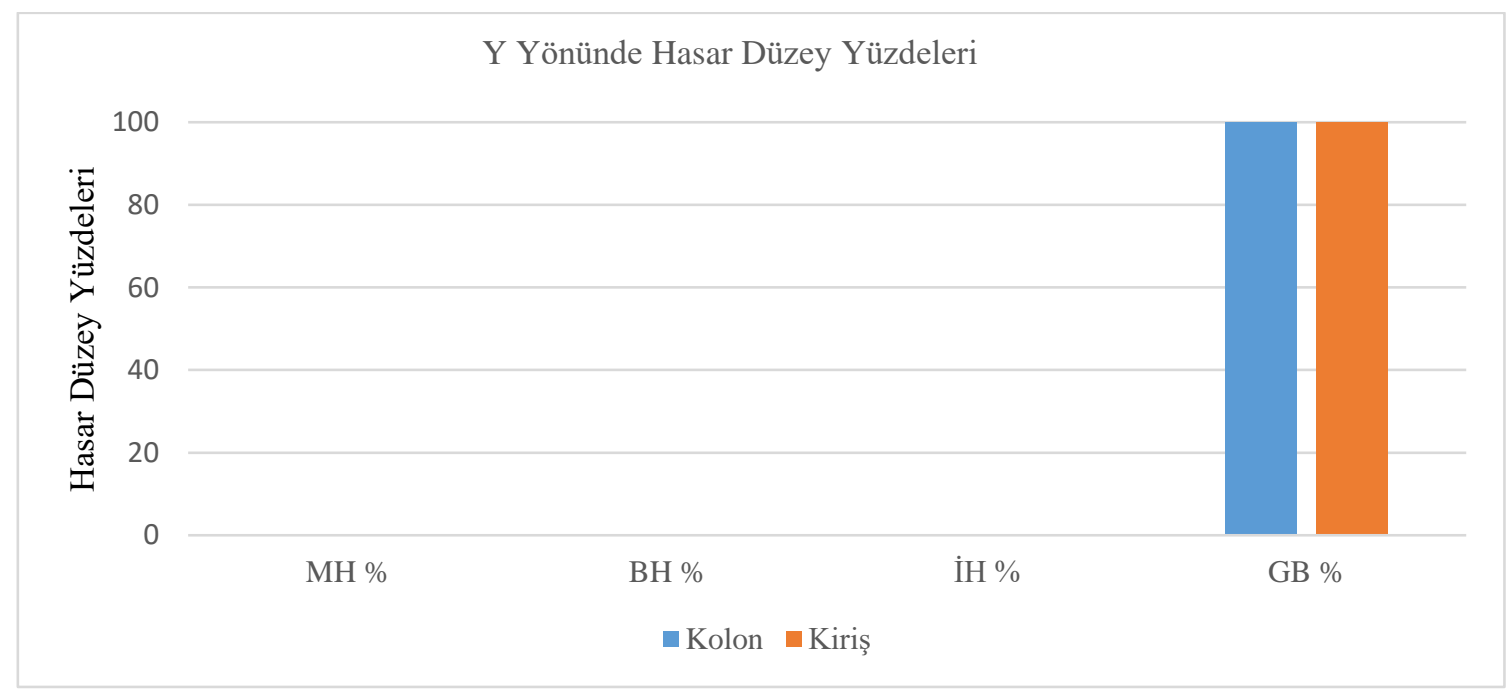

Şekil 8. Y yönünde taşıyıcı sistem elemanları hasar düzey yüzdeleri 


\section{Eurocode 8'e Göre 8 Katlı Binanın Performans Değerlendirilmesi}

\subsection{Bina Bilgileri}

Bölüm 2'de DBYBHY-2007'ye göre performans değerlendirilmesi yapılan bina modeli bu kısımda Eurocode 8'e göre analiz edilmiş ve eleman hasar düzeyleri belirlenmiştir. Mevcut bina tam detaylı bilgi düzeyinde incelenmiştir. Bina geometrisi, malzeme bilgileri ve kesit özellikleri Bölüm 2'de analiz edilen bina ile aynı özellikleri taşımaktadır. Depreme ve zemine ilişkin parametreler ise Eurocode 8'de belirtildiği şekilde kullanılmıştır.

\subsection{Binaya Etkiyen Deprem Yüklerinin Hesabı}

Bina mod şekillerinin ve titreşim periyotlarının belirlenebilmesi için Sap2000 V.16'da 24 modlu bir analiz yapılmış ve binanın x yönüne ait birinci doğal titreşim periyodu $1.38850 \mathrm{sn}, \mathrm{Y}$ yönüne ait birinci doğal titreşim periyodu ise 1.35082sn bulunmuştur. Katlara etkiyen deprem kuvvetleri Eurocode 8 Bölüm 3'e göre hesaplanarak X ve Y yönü için elde edilen değerler Şekil 7'de gösterilmiştir [13].

\subsection{Kirişlerde ve Kolonlarda Plastik Mafsal Özelliklerinin Tanımlanması}

Kirişlerin ve kolonların plastik mafsal özellikleri SAP2000 V.16 programında Assign-Frame-Hinges menüsünden ilgili elemanın net açıklıklarının uçlarına tanımlanmıştır. Programa plastik mafsal özelliklerinin veri girişi Bölüm 2'ye göre yapılmış ve kiriş ve kolonlar için elde edilen değerler Şekil 9'da verilmiştir [12].

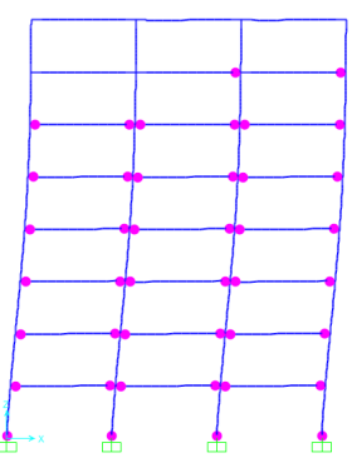

a) X yönü

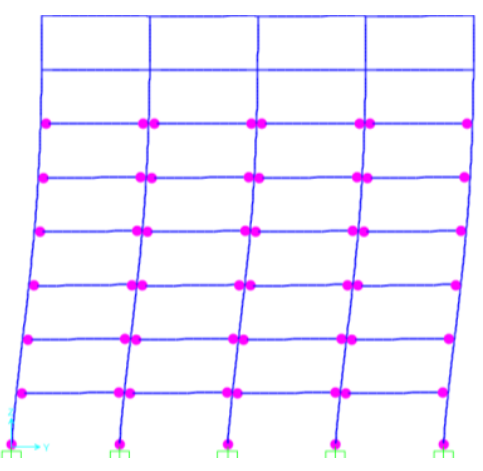

b) Y yönü

Şekil 9. X ve Y yönünde yapılan itme analizi sonucunda binada oluşan plastik kesitler

\subsection{Artımsal İtme Analizi (Pushover Analiz)}

Statik itme analizi iki kısımdan oluşmaktadır. İlk kısımda düşey yükler $(\mathrm{G}+0.3 \mathrm{Q})$ dikkate alınarak doğrusal olmayan analiz, ikinci kısımda ise yatay yükler altında artımsal itme analizi yapılır. Yapılan artımsal itme analizi sonucunda X ve Y yönünde elde edilen statik itme eğrileri Şekil 10’da verilmiştir. 


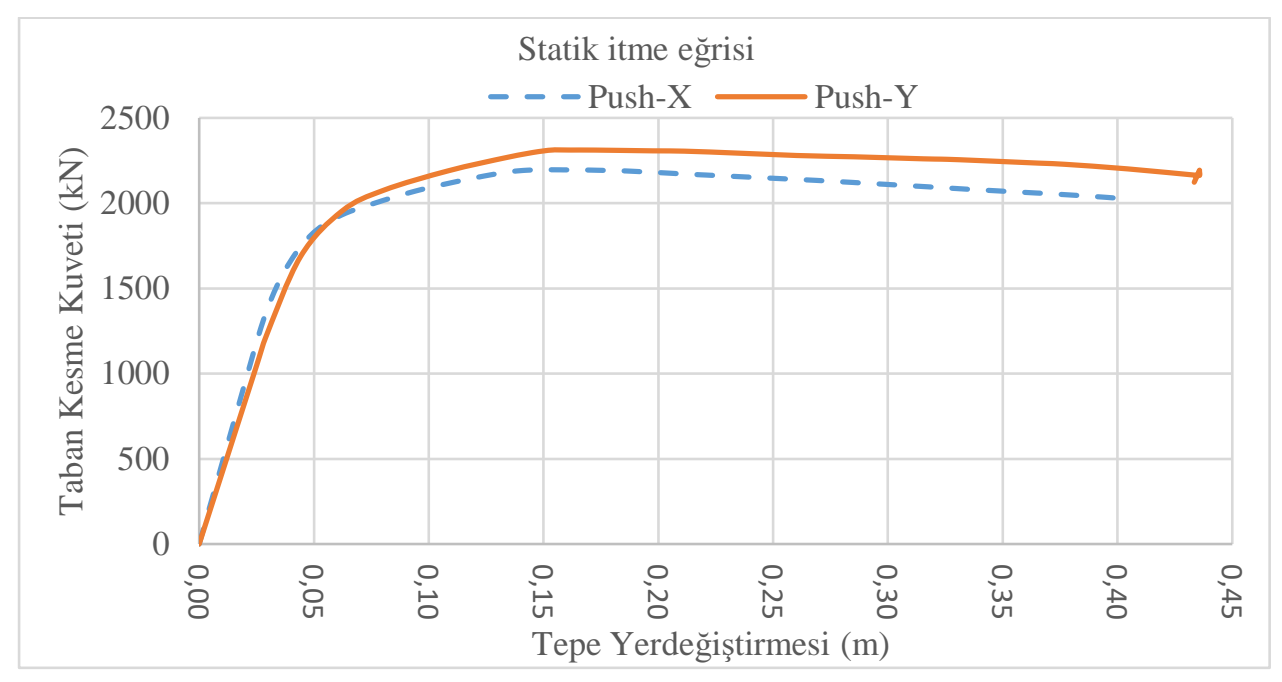

Şekil 10. X ve Y yönü için statik itme eğrisi

\subsection{Hedef Yer Değiştirmenin Hesabı}

Eurocode 8'e göre hedef yer değiştirmenin hesabı, EN 1998-1, denklem B.3'te belirtilen esaslara göre yapılmış ve ilgili hesaplamalara ait değerler $X$ yönünde $\Gamma=1.286, \mathrm{dt}^{*}=0.263(\mathrm{~m}), \mathrm{dt}=0.338(\mathrm{~m})$ ve $\mathrm{Y}$ yönünde ise $\Gamma=1.275, \mathrm{dt}^{*}=0.266(\mathrm{~m}), \mathrm{dt}=0.339(\mathrm{~m})$ verilmiştir [13].

$\mathrm{X}$ ve Y yönünde bulunan hedef yer değiştirmeye ulaşıncaya kadar yeni bir itme analizi SAP2000 V.16 programı yardımıyla yapılmıştır. Bu analiz sonucunda oluşan plastik dönme ve iç kuvvet talepleri belirtilen programdan alınmıştır. X yönünde yapılan itme analizinden binanın hedef yer değiştirmesine ulaşıldığı adımda oluşan plastik mafsallar Şekil 9'da görülmektedir.

\subsection{Kolonların ve Kirişler İçin Plastik Dönme Ve Sınır Değerlerinin Hesabı}

Kolonlar için P-M2-M3 mafsal tanımı ve kirişler için ise M3 mafsal tanımı yapılarak itme analizi gerçekleştirilmiştir. Her iki yönde hedef yer değiştirmeye ulaşıncaya kadar yapılan itme analizi sonucu her bir kolon ve kiriş elemanları için plastik dönme değerleri elde edilmiştir. Ayrıca, Eurocode 8 Bölüm 3 EK A.3.1'de belirtilen sınır değerler, göçmeye yakın sınır durumu (NC) için Denk. 4.3, ağır hasarlı sınır durumu(SD) için Denk. 4.1 ile elde edilen değerin 3/4’ü ve sınırlı hasar durumu(DL) için Denk. 4.12 kullanılarak elde edilmiştir [13].

\subsection{Eleman Hasar Düzeylerinin Belirlenmesi}

Artımsal itme analizi sonucu elde edilen plastik dönme değerleri, Eurocode 8 Bölüm 3'te belirtilen esaslara göre hesaplanan sınır değerler ile birlikte sırasıyla Şekil 11 ve Şekil 12'de verilmiştir. Ayrıca, kritik katta bulunan kirişler için plastik dönme değerleri ve sınır değerleri sırasıyla Şekil 3.13 ve 3.14'te verilmiştir [13]. 


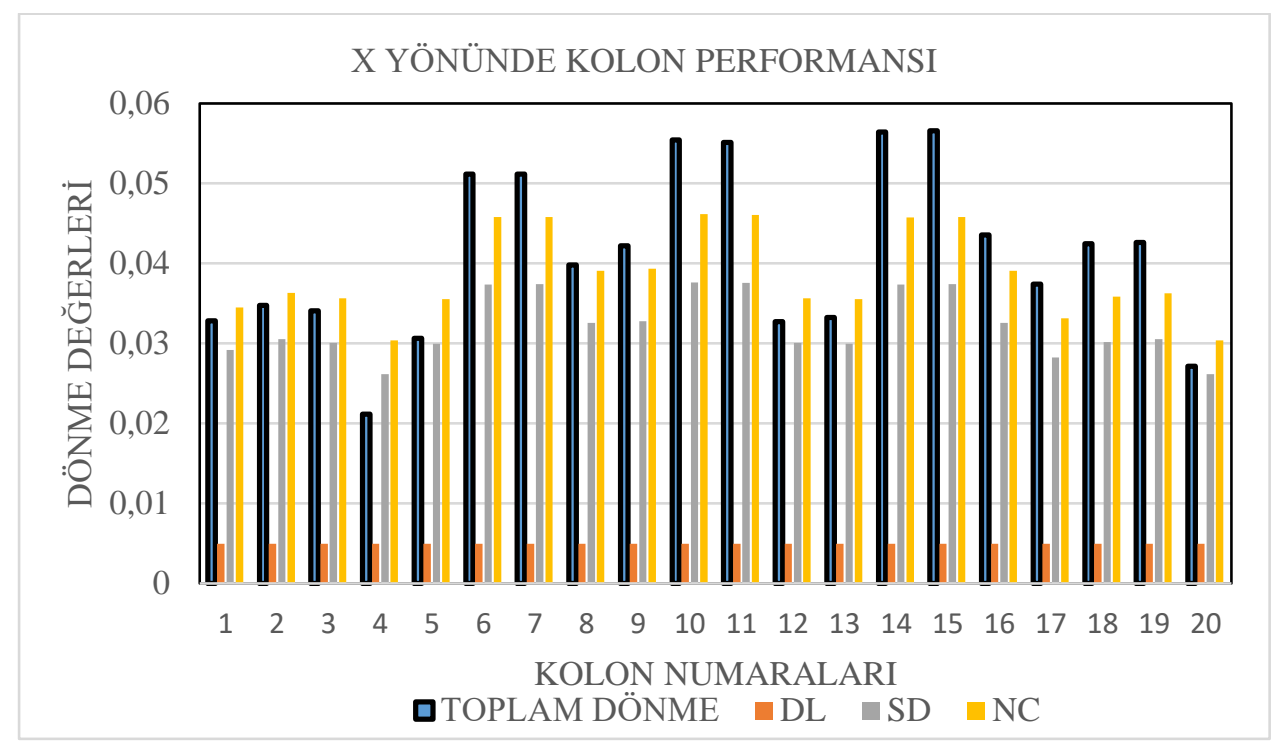

Şekil 11. X yönü artımsal itme analizi yöntemi ile belirlenen kritik kattaki kolonların hasar düzeyleri

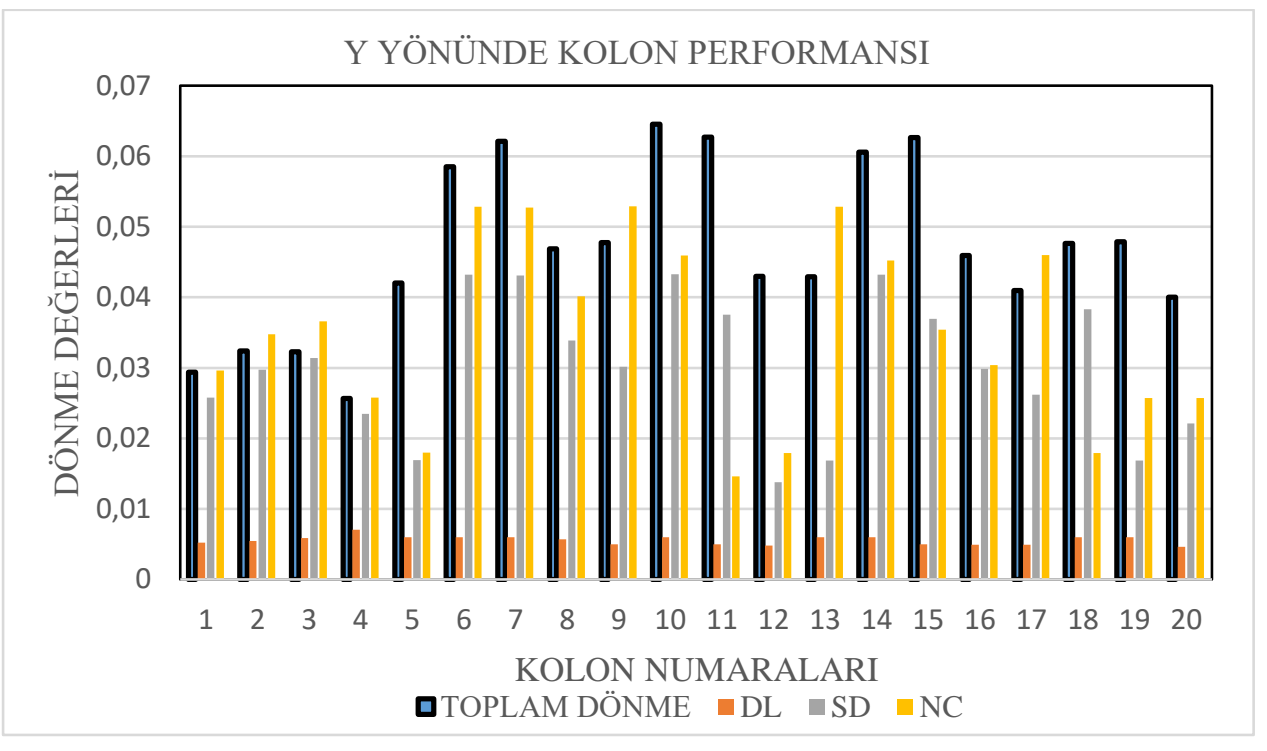

Şekil 12. Y yönü artımsal itme analizi yöntemi ile belirlenen kritik kattaki kolonların hasar düzeyleri 


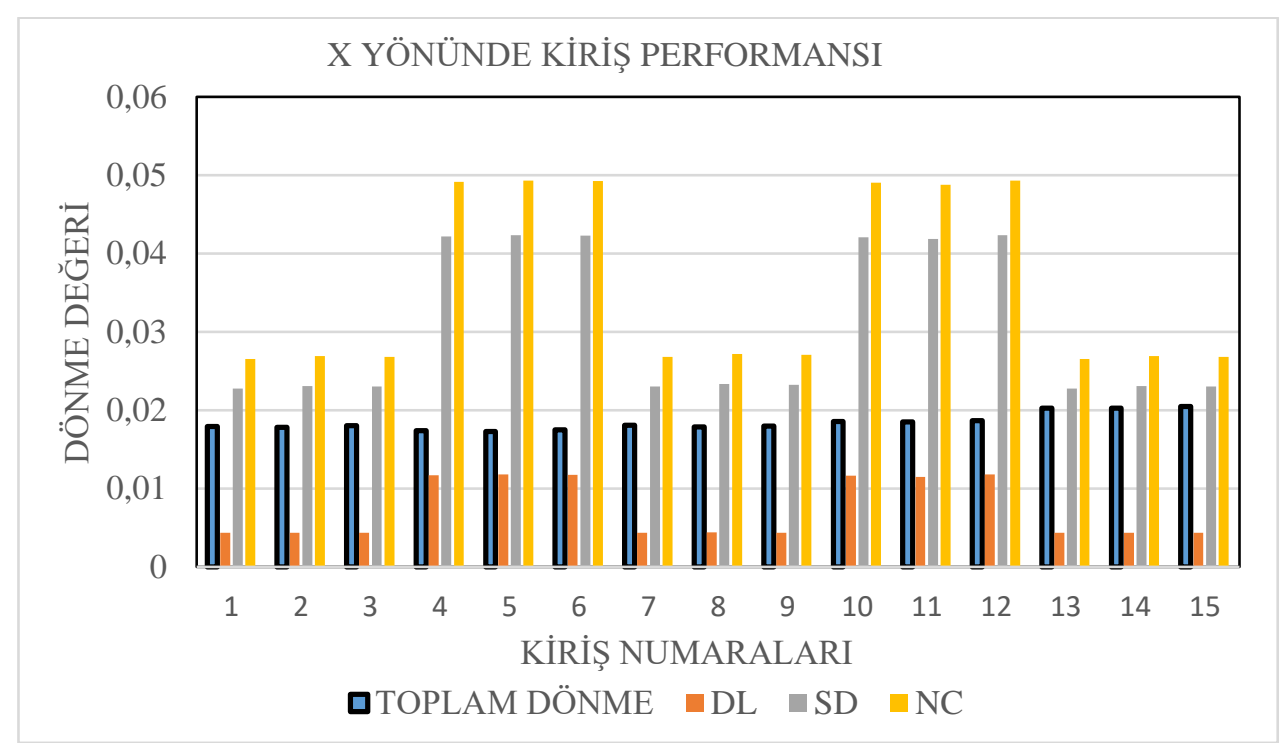

Şekil 13. X yönü artımsal itme analizi yöntemi ile belirlenen kritik kattaki kirişlerin hasar düzeyleri

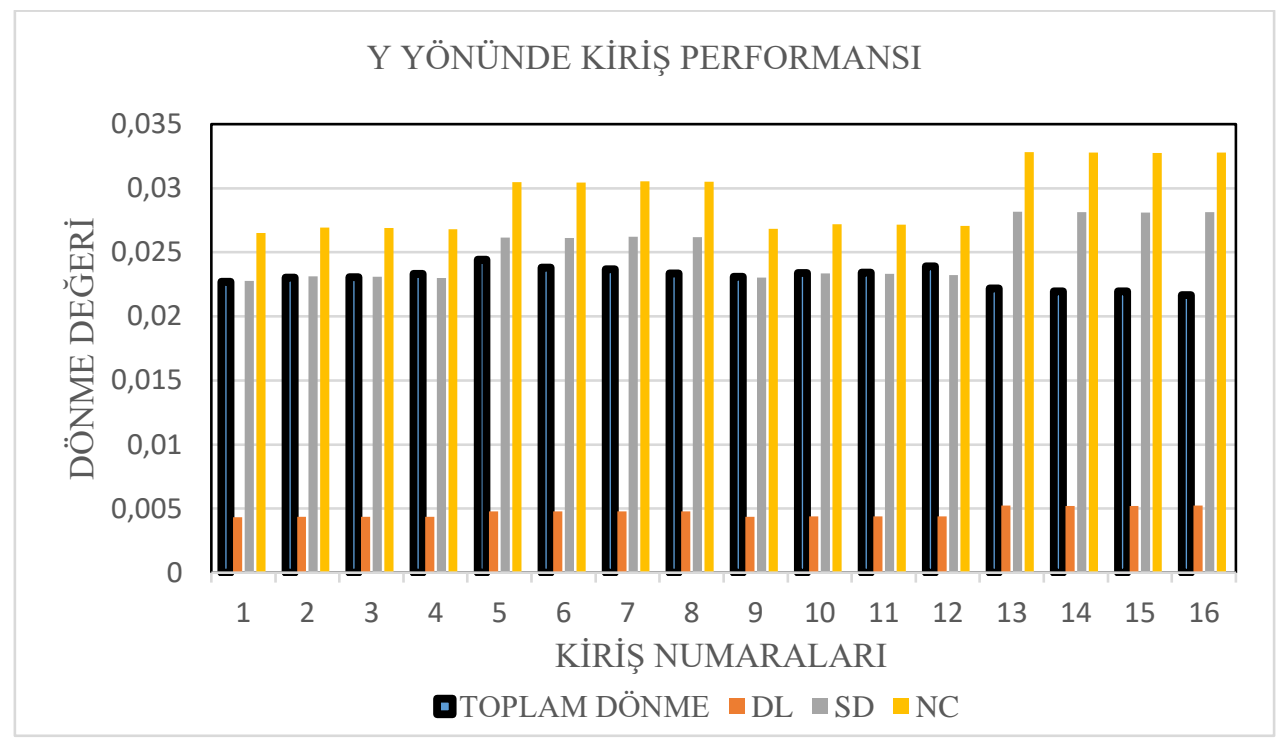

Şekil 14. Y yönü artımsal itme analizi yöntemi ile belirlenen kritik kattaki kirişlerin hasar düzeyleri

Artımsal itme analizi sonucu elde edilen plastik dönme değerleri, Eurocode 8 Bölüm 3'te belirtilen esaslara göre hesaplanan sınır değerler ile karşılaştırılarak kritik katta bulunan kolonlar ile kirişlerin her iki doğrultudaki eleman hasar düzeyleri belirlenmiş ve sırasıyla Şekil 15 ve Şekil 16'de verilmiştir.

Şekil 15 ve Şekil 16'da görüldüğü üzere X yönünde kritik kattaki kolonların \%5'i belirgin hasar düzeyinde, \% 35'i ileri hasar düzeyinde, \% 60’1 göçme bölgesi hasar düzeyinde iken Y yönünde ki kritik kattaki kolonların \% 25 'i ileri hasar düzeyinde, \% 75'i göçme bölgesi hasar düzeyinde çıkmıştır. Kritik kattaki kirişler incelendiğinde $\mathrm{X}$ yönünde kirişlerin \% 100'ünün belirgin hasar düzeyinde, Y yönündeki kirişlerin ise \% 68.75'inin belirgin hasar düzeyinde \% 31.25'inin ise ileri hasar düzeyinde olduğu görülmüştür. 


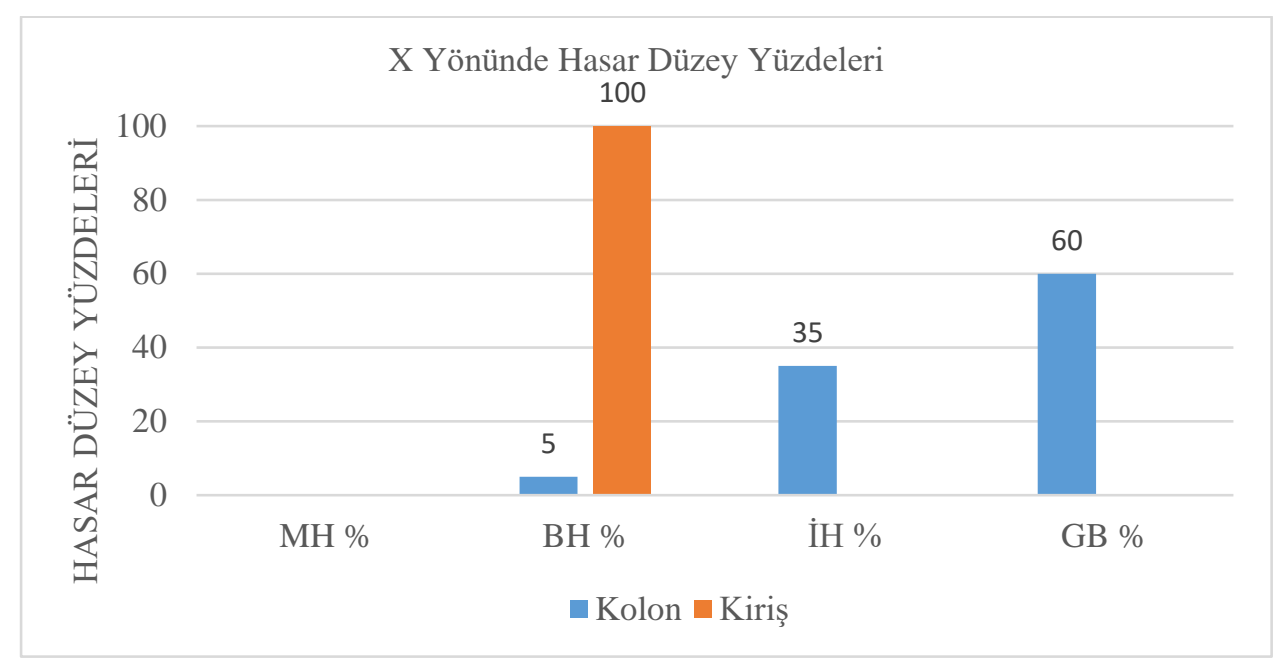

Şekil 15. X doğrultusunda taşıyıcı sistem elemanlarının hasar düzey yüzdeleri

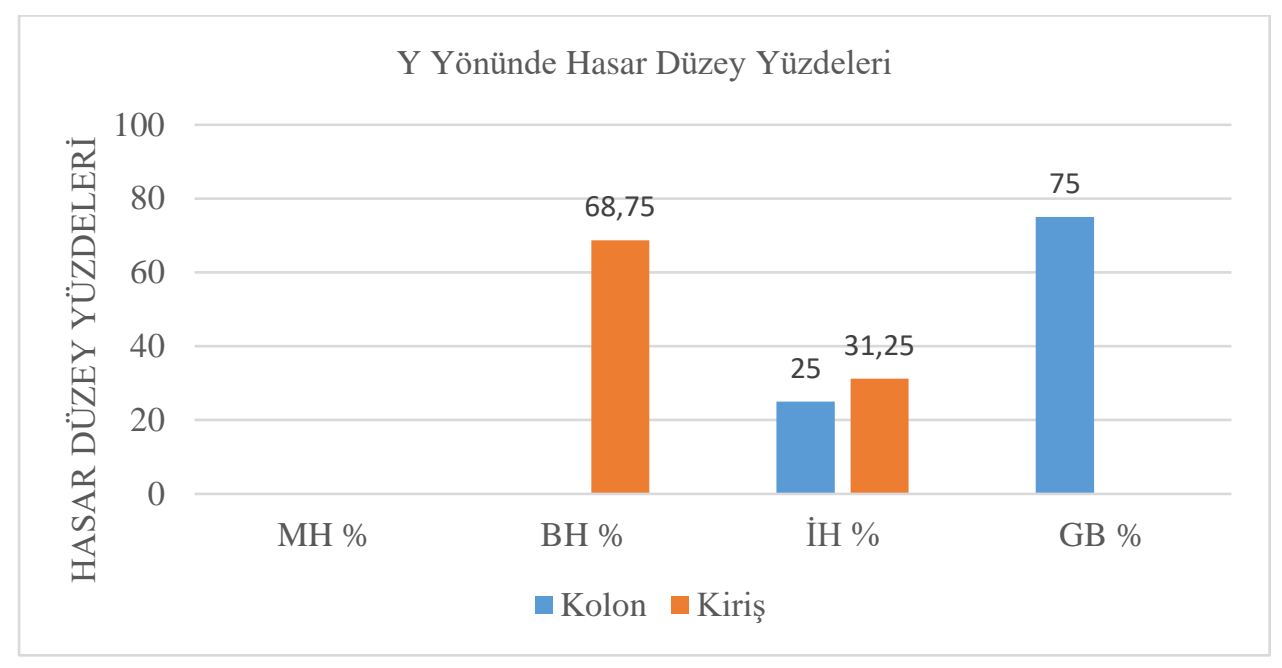

Şekil 16. Y doğrultusunda taşıyıcı sistem elemanlarının hasar düzey yüzdeleri

\section{SONUÇLAR}

Bu çalışmada mevcut 8 katlı binanın DBYBHY-2007 ve Eurocode 8 yönetmeliklerinde belirtilen esaslara göre performans analizleri artımsal itme analizi yöntemi kullanılarak yapılmıştır.

8 katlı mevcut bina önce SAP2000 programında DBYBHY-2007'ye göre tasarlanmış ve artımsal eşdeğer deprem yükü yöntemi ile itme analizi uygulanarak performans değerlendirilmesi yapılmıştır. Analiz ve değerlendirmeler sonucunda her iki yönde kritik kattaki kolonların tamamının göçme bölgesinde olduğu ve y yönündeki kirişlerinde tamamının göçme bölgesinde olduğu belirlenmiştir. Bu sonuçlara ve DBYBHY-2007 madde 7.7'de belirtilen performans kriterlerine göre binanın "Göçme Durumu" performans seviyesinde olduğu görülmüsşür. Eurocode 8'e göre ise kritik kattaki kolonların x yönünde \% 60'ının göçme bölgesinde ve Y yönünde \% 75'inin göçme bölgesinde olduğu ancak kritik kattaki kirişlerin göçme bölgesinde olmadığı, $\mathrm{X}$ yönünde \% 100'ünün ve Y yönünde \% 68.75'inin belirgin hasar bölgesinde olduğu belirlenmiştir. Analiz ve eleman düzeyinde performans değerlendirmeleri sonucunda 8 katlı örnek binaya ait DBYBHY-2007 ve Eurocode 8'e göre değerlendirilen eleman performans düzeylerinin özellikle düşey taşıyıcı elemanlarda birbirine yakın olduğu ancak DBYBHY-2007'nin daha güvenli tarafta kaldığı görülmüştür. 


\section{KAYNAKLAR}

[1] KIRAN, F., "Binaların Performans Analizi İçin Kullanılan Doğrusal ve Doğrusal Olmayan Analiz Yöntemlerinin İncelenmesi”, Çukurova Üniversitesi Fen Bilimleri Enstitüsü Yüksek Lisans Tezi, Adana, 2010.

[2] BİROL, M.S., “Az ve Çok Katlı Yapılar da Bilgi Düzeyi Seviyesinin Binanın Performansına Etkisi”, Sakarya Üniversitesi Fen Bilimleri Enstitüsü Yüksek Lisans Tezi, Sakarya, 2010.

[3] GÖKALP, E., "Betonarme Yapıların Performans Analizlerinde Kullanılan Yöntemlerin Karşılaştırılması”, Celal Bayar Üniversitesi Fen Bilimleri Enstitüsü Yüksek Lisans Tezi, Manisa, 2009.

[4] YILDIRIM, F. G., "Bodrum ve Sekiz Katlı Bir Konut Binasının Betonarme Perde ve Kolonlardan Oluşan Taşıyıcı Sisteminin Deprem Performansının Belirlenmesi”, İstanbul Teknik Üniversitesi Fen Bilimleri Enstitüsü Yüksek Lisans Tezi, İstanbul, 2011.

[5] BJARNASON, J.Ö., "Pushover Analysis of an Existing Reinforced Concrete Structure", Reykjavik University Master Thesis, Reykjavik, 2008.

[6] BOZAN, A., "Mevcut Çok Katlı Yapının Statik İtme (pushover) Yöntemi İle Analizi, Yüksek Lisans Tezi", Sakarya Üniversitesi Fen Bilimleri Enstitüsü Yüksek Lisans Tezi, Sakarya, 2008.

[7] EKİCI, E., "Comparison of Observed Structural Damages and Code Given Structural Performance Limits", İstanbul Teknik Üniversitesi Fen Bilimleri Enstitüsü Yüksek Lisans Tezi, İstanbul, 2011.

[8] TOPRAK, A, E., "Code-based Evaluation of Seismic Performance Levels of Reinforced Concrete Buildings With Linear and Non-linear Approaches", İstanbul Teknik Üniversitesi Fen Bilimleri Enstitüsü Yüksek Lisans Tezi, İstanbul, 2008.

[9] TEMÜR, F., "Statik İtme (pushover) Yöntemi Kullanılarak Yapıların Analizi”, Sakarya Üniversitesi Fen Bilimleri Enstitüsü Yüksek Lisans Tezi, Sakarya, 2007.

[10] ÖZTÜRK, B., "Seismic drift response of building structures in seismically active and near-fault regions", Purdue University PhD Thesis, W. Lafayette, Indiana, USA, 2003.

[11] DBYBHY, "Deprem Bölgelerinde Yapılacak Binalar Hakkında Yönetmelik”, T. C. Çevre ve Şehircilik Bakanlığı, Ankara, 2007.

[12] SAP2000 V.16.1, Computers and Structures, Inc., http://www.csiberkeley.com, 1995 University Avenue Berkeley, California 94704 USA,. 1978-2010.

[13] EUROCODE 8, "Design of Structures for Earthquake Resistance Part 3: Assessment and Retrofitting of Buildings”, Doc. CEN/TC250/SC8/N388B. Comité Européen de Normalisation, Bruxelles, 2004. 